\title{
Improving on Defaults: Helping Pension Participants Manage Financial Market Risk in Target Date Funds
}

\author{
John A. Turner (D) and Bruce W. Klein * \\ Pension Policy Center, Washington, DC 20016, USA; jaturner49@aol.com \\ * Correspondence: brucewklein@aol.com
}

Citation: Turner, John A., and Bruce W. Klein. 2021. Improving on Defaults: Helping Pension Participants Manage Financial Market Risk in Target Date Funds. Risks 9: 79. https://doi.org/ 10.3390/risks9040079

Academic Editors: Jorge Miguel Bravo and Tomas Kliestik

Received: 29 December 2020

Accepted: 14 April 2021

Published: 19 April 2021

Publisher's Note: MDPI stays neutral with regard to jurisdictional claims in published maps and institutional affiliations.

Copyright: (c) 2021 by the authors. Licensee MDPI, Basel, Switzerland. This article is an open access article distributed under the terms and conditions of the Creative Commons Attribution (CC BY) license (https:// creativecommons.org/licenses/by/ $4.0 /)$.

\begin{abstract}
The central issue of this paper is analysis and resulting proposals to help unsophisticated pension participants achieve pension portfolios that match their level of risk aversion when there is a large amount of unexplained heterogeneity in risk aversion. Target date funds are commonly used as the default investment in defined contribution plans in the U.S., UK and other countries. These funds recognize that individuals usually should hold less risky investment portfolios as their expected retirement date approaches because their ability to bear financial market risk declines as the time horizon decreases. However, these funds do not account for differences in risk aversion among people with the same target date. Empirical studies find large amounts of unexplained heterogeneity in risk aversion. Target date funds cannot deal with this issue simply by sorting people into demographic groupings, other than age, that are known to affect risk aversion, such as gender. Financial education can help people do a better job of managing financial market risk in their pension portfolios, but we argue that it is unreasonable to expect millions of pension participants to attain advanced levels of financial literacy. This paper considers three innovations in target date funds that can help individual pension participants do a better job of managing financial market risk. The analysis can be applied to other situations where defaults are used for investing pension participants' portfolios. The paper suggests new lines of research relating to individual differences in risk aversion.
\end{abstract}

Keywords: investment risk; risk aversion; target date funds; financial advice; financial literacy; financial education; robo advice

JEL Classification: G11; G51; J16; J26

With the growth of defined contribution plans, pension participants must make more decisions concerning the management of financial market risks. One way of dealing with the issue is to launch financial education programs. We argue that, while financial education to provide a basic level of financial literacy is desirable, it is unreasonable to expect millions of people to achieve the level of financial literacy needed to construct well-diversified, low-fee portfolios that are appropriately aligned with each person's riskaversion level. For this reason, we consider alternatives to financial education and financial literacy. The central issue of our paper is analysis and proposals to help unsophisticated pension participants achieve pension portfolios that match their level of risk aversion when there is a large amount of unexplained heterogeneity in risk aversion.

Market innovations have addressed the lack of financial literacy by simplifying the choices pension participants must make. Financial markets have progressed from offering individual stocks, to mutual funds, to index funds, to target date funds, also called retirement date funds, and lifecycle funds (Thrift Savings Plan 2021).

Target date funds are diversified mutual funds that gradually adjust their portfolios as the target date approaches, reducing their exposure to stocks and increasing their exposure to bonds. For some funds, the adjustment ends at the target date, which is the person's expected retirement date, while for others the adjustment continues into retirement. Thus, 
while a person might need to select thirty stocks to construct a well-diversified domestic equity portfolio, and four index mutual funds to construct a well-diversified total portfolio, they only need to select one target date fund. Further, that fund automatically rebalances to maintain the desired level of risk and automatically adjusts its risk level over time as the target date approaches.

Target date funds (TDFs), however, currently ignore heterogeneity in risk aversion beyond factors related to age or expected date of retirement. They focus only on retirement dates but exclude other known factors that are associated with differences in risk aversion, such as gender.

The paper analyzes three proposals to personalize target date funds for improving risk management by individual participants. The first section discusses literature relating to heterogeneity in risk aversion. It also briefly discusses evidence relating to the effectiveness of financial education in helping people make complex financial decisions, such as constructing an investment portfolio. The second section presents a simple model of the investment decisions pension participants face, focusing on heterogeneity in risk aversion. The third section describes target date funds in more detail. The fourth section presents three proposals that would enable pension participants in target date funds to better manage the investment risks. The fifth section offers concluding comments.

The contribution of this paper is that it proposes changes to target date funds that would allow pension participants using those funds to better manage the financial market risk they bear, given their level of risk aversion. The analysis can be applied to other situations where defaults are used for investing pension participants' portfolios. Promoting financial literacy through financial education is a difficult and costly task. While greater financial literacy and greater financial education is a possible approach, the paper argues that its three proposals are more likely to be effective.

\section{Relevant Literature}

A key element of the argument of this paper relates to the empirical evidence as to heterogeneity in risk aversion. Khemka et al. (2020) find that current target date funds (TDFs) are sub-optimal due to heterogeneity in risk aversion. Using simulations, they show that target date funds could be substantially improved in terms of expected utility if the TDFs were better aligned to participants' risk aversion levels.

Harrison et al. (2007) use a field experiment to elicit levels of risk aversion, documenting a considerable amount of heterogeneity in risk aversion. They do not find gender to be a factor explaining differences in risk aversion. They do find a considerable amount of unexplained heterogeneity in risk aversion.

Cohen and Einav (2007), in an empirical study, find women to be on average more risk averse than men. On average, women have a coefficient of absolute risk aversion that is 16 percent greater than the average coefficient for men.

Campbell (2006) writes that risk aversion is affected by wealth, income, age, education, and race. Interestingly, he does not include gender. Studies indicate that female pension participants, and more generally female investors, tend to be more risk averse than male pension participants, even controlling for age, income, and marital status, and as a result are less likely than men to invest in stocks (Bajtelsmit and Bernasek 1996; Bajtelsmit and VanDerhei 1997; Hinz et al. 1996; Mitchell and Turner 2010; Martensen 2008; Lusardi and Mitchell 2008; Almenberg and Dreber 2015; Dawson 2020; Fey et al. 2020). Bank of America (2020) finds that among 4.6 million 401(k) participants for whom it is their plan's record keeper, on average, $69 \%$ of women are invested in equities, compared to $76 \%$ of men. Li et al. (2021) find that the gender difference in stock market participation also exists in China, and it exists, holding various characteristics of households constant. Borghers et al. (2009) find that people who are less agreeable in intertemporal relationships and more ambitious are less risk averse. They also find that psychological traits play only a small role in the gender differences in risk aversion. 
While this literature finds a correlation between gender and level of risk aversion, the reasons for this correlation are not well understood. A possible factor that, to our knowledge, has not been explored is that women have greater risks to their labor market income, in part because they traditionally have had greater family-care responsibilities.

Ellevest is a robo advisor that focuses on providing financial advice to women, which now has more than USD 1 billion in assets under management (McGrath 2021). Robo advisors are investment management companies that use computer programs, rathe than human advisors, to construct and manage investment portfolios. "Women tell us that they place higher value on the opportunity to reach their goals than on speculative investments (taking greater risks)", according to Ellevest Chief Investment Officer Sylvia Kwan (Tepper 2020).

Watson and McNaughton (2007), in an empirical study of employees of Australian universities, find that though the gender difference in risk aversion is statistically significant, its economic impact on portfolio selection is small. In their regressions, the adjusted $\mathrm{R}^{2}$ is low, never exceeding 0.03 , indicating that most of the variation in risk aversion is unexplained by their explanatory variables, including age, gender, and income. Similarly, Guiso and Paiella (2007) find a high level of unexplained heterogeneity in risk aversion.

This finding of a large degree of unexplained heterogeneity in risk aversion is important for target date funds for two reasons. First, a large amount of heterogeneity in risk aversion remains, even after controlling for age. Second, an attempt to improve the personalization of target date funds beyond just the age factor, such as gender, would not address the wide variation in risk aversion. For this reason, we do not recommend adding demographic characteristics beyond age to the target date fund structure; instead, we propose changes that would more directly measure differences in risk aversion.

Financial education is an alternative approach used to help participants manage investment risk in target date funds. Financial education is a relatively expensive approach and, so far, has had limited success, as evidenced by the generally low levels of financial literacy (Turner and McCarthy 2000; Turner and Korczyk 2004; Lusardi and Mitchell 2014). Lusardi et al. (2017) evaluate the effectiveness of financial education programs. They find that one-time financial education programs tend to be ineffective, but that programs that provide follow-up tend to be more effective.

\section{Investment Decisions}

This section briefly describes the problem for unsophisticated individuals and for target date funds of dealing with risk aversion. Constructing a well-diversified, low-fee portfolio that is appropriate for an individual's level of risk aversion is an inherently complex task. The task is made even more difficult, and probably impossible, for many people by their financial illiteracy.

The net rate of return after fees rp on the pension depends on the individual's asset allocation decision as to the portfolio mix between equities and bonds, where $\alpha$ is the percentage of the person's portfolio in equities, re is the rate of return on equities and rb is the rate of return on bonds. It also depends on the investment management fees the individual pays fe and fd on equities and bonds.

$$
\mathrm{rp}=\alpha \mathrm{re}(1-\mathrm{fe})+(1-\alpha) \mathrm{rb}(1-\mathrm{fd})
$$

The individual faces a decision as to how much to invest in equities. The amount of risk he or she is willing to bear is affected by the individual's level of risk aversion $\varrho$.

$$
\alpha=\alpha(\varrho)
$$

Without specifying a causal relationship of gender, the individual's level of risk aversion $\varrho$ relating to their retirement savings can be predicted currently by their age a, 
expected retirement age ar, gender $\mathrm{g}$, financial literacy $\mathrm{l}$, level of trust $\mathrm{t}$ in financial markets, and prior experience e investing in stock.

$$
\varrho=\varrho(\mathrm{a}, \mathrm{ar}, \mathrm{g}, \mathrm{l}, \mathrm{t}, \mathrm{e})
$$

Guiso et al. (2004) find that households that are reluctant to trust others and those without prior experience investing in stocks are less likely to select stocks. Lusardi and Mitchell (2014) survey studies showing that financial literacy increases stock market participation. Robo advisors, discussed further later, presumably use a similar model for trying to understand the amount of risk aversion of their clients. For many individuals, the decision as to how to invest their pension account is a one-time entry cost because many do not make subsequent changes in their asset allocation (Campbell 2006).

The complexity of the investment decision is also affected by a decision at the intensive margin as to which equities to invest in. The complexity $x \alpha$ of the investment decision as to which stocks to invest in is increased by the number $\mathrm{n} \alpha$ of portfolio options, such as international stocks, small cap stocks, and tech stocks (Choi et al. 2007; Duarte and Hasting 2009). Shen and Turner (2018) demonstrate that the five investment options of the Thrift Savings Plan for federal government workers, members of Congress, and the military are sufficient to provide a well-diversified portfolio. The cognitive costs of greater portfolio choice can lead to worse saving and retirement income choices. With a greater number of choices, the participant must decide how much $\alpha \mathrm{n}$ to invest in each option chosen from the options of a particular provider. Other aspects of complexity are the complexity of the fee structure $\mathrm{xF}$ and the complexity of language $\mathrm{xL}$ used to explain different financial products and their fees, where complexity in fee disclosure is increased by using difficult vocabulary and long sentences. Muller and Turner (2016) present a formula that can be used to rate the complexity of the language relating to fee disclosures, based on sentence length and complexity of the vocabulary. Complexity occurs both at the intensive margin relating to a particular pension provider, and at the extensive margin based on the number of providers np. Thus, the complexity of the investment decision $x \alpha$ can be represented by the following

$$
\mathrm{x} \alpha=\mathrm{X}(\mathrm{n} \alpha \mathrm{xF}, \mathrm{xL}, \mathrm{np})
$$

The problem can be simplified by investing the entire pension portfolio in a target date fund, but in that case, it is assumed by the target date fund provider that the level of risk aversion is only affected by the person's expected retirement age ar, which translates into their expected year of retirement. Thus, in target date funds, the percentage invested in equity $\alpha$ tdf is only affected by the person's expected retirement age ar, as measured by the year they expect to retire

$$
\alpha \mathrm{tdf}=\alpha(\operatorname{ar})
$$

Individuals lacking financial literacy can hire a financial adviser to help them with their investment decisions, but that generally is too expensive for people with small portfolios. They can invest in a target date fund, but that only differentiates people's risk aversion by age. Alternatively, in the U.S., Canada and a number of other countries, they can enroll in an individual account pension through a robo advisor. Robo advisors generally charge substantially lower fees than human advisors (Fisch et al. 2019).

\section{Target Date Funds}

Target date funds have grown to play an increasingly important role in financial market investing. They have grown in number from 63 in the year 2000 to 2778 in 2019 (Massa et al. 2021). In the United States, as of 2015, target date funds were offered by 90 percent of 401(k)-type plans, which are the most common type of U.S. defined contribution plan (Katzeff 2016). A Mercer study found that target date funds had USD 1.43 trillion in assets as of 31 March 2017, compared to USD 0.5 trillion five years earlier (Lloyd 2018). More than half of all 401(k) participants have at least some money in target date funds 
and approximately 24 percent of the total assets in $401(\mathrm{k})$ accounts are in this type of fund (Shoven and Walton 2020).

Target date funds typically are offered in five-year increments. For example, plans will have a target date fund for 2030, 2035, and 2040. The Thrift Savings Thrift Savings Plan (2021) for federal government employees is typical of U.S. plans in this respect.

Turner (2003) discusses errors that workers make in managing their 401(k) plans, which include excessive risk or excessive conservatism. Mitchell and Utkus (2020) find that target date funds tend to result in better investment decisions than participants make on their own. These funds raise equity shares, boost bond exposures, curtail cash/company stock holdings, and reduce idiosyncratic risk. They find that low-cost target date funds may enhance retirement wealth by as much as 50 percent over a thirty-year horizon, a result that supports the strategy of alternatives to financial literacy.

The widespread use of auto enrollment to increase pension coverage has contributed to target date fund growth. In the U.S., the Pension Protection Act of 2006 authorizes retirement plans to use a target date fund as a default if a participant has not selected an option, such as may happen in auto enrollment. With defaults, the target date generally is based on the year the participant reaches age sixty-five. In the U.S., target date funds are the default option in the Thrift Savings Plan (TSP) for federal government workers (Turner et al. 2016). In the UK, they are the default option in Nest, a government-sponsored pension fund, which is the largest UK pension fund by number of participants (Turner et al. 2018). Target date funds as a default are part of a global move toward defaults in defined contribution plans (Brown and Davies 2020).

A defining characteristic of target date funds is that they automatically reduce the risk of their portfolios as retirement approaches, decreasing the percentage of equities in the portfolio and increasing the percentage of bonds. They assume that people want to transition into lower risk portfolios as retirement approaches, reducing the risk of a large financial loss when they have little time to recover. A further reason is that, as workers approach retirement, their human capital accounts for a decreasing share of their wealth, while their financial market investments account for an increasing share of their wealth.

Target date funds have been criticized for not considering heterogeneity in risk aversion for workers with the same retirement target date (Jacobs 2013; Luxenberg 2013; Lloyd 2018; Shoven and Walton 2020). Lloyd (2018), recognizing that problem, has proposed replacing target date funds - when they reach a certain asset level—with managed accounts. He argues that the higher fees associated with managed accounts can be justified by the better outcomes related to improved personalization of portfolios. Sophisticated participants can adjust the risk of their portfolios by picking a fund with a later or earlier target date; however, most participants lack that level of sophistication.

The paper now considers three proposals for dealing with the unexplained heterogeneity in risk aversion that address issues of risk framing and management among pension participants. These proposals are not mutually exclusive but instead build on each other.

While Choi et al. (2020) discuss characteristics of optimal defaults, we discuss modifications to the framework of defaults that we argue may be more effective. Our paper is more closely related to the paper by Carroll et al. (2005) on active choice as a superior option in some circumstances compared to defaults. They find that active decisions are optimal when participants have highly heterogenous savings propensities. With defaults, because of inertia, participants tend to stick with defaults even though that situation may differ substantially from an optimal choice. We argue that active decisions relating to portfolio risk are optimal when participants have highly heterogeneous levels of risk aversion, but only if it is unexplained heterogeneity. If the heterogeneity is explained, the default can be structured to take that into account.

\section{Proposal One: Offer Target Date Funds with Three Levels of Risk for Every Target Date}

A relatively simple, low-cost change that would improve the personalization of target date funds would be to have three risk-level options-lower, medium, and higher. Instead 
of having one decision based only on the date of the target date fund, people would have two decisions-target date and level of risk.

A few employers and mutual funds have already implemented this proposal, offering employees a greater opportunity to personalize their risk exposure while retaining the advantages of a target date fund. For example, in the UK, The People's Pension (2016) offers three choices-a conservative fund, a balanced fund, and an adventurous fund. Workers choose which fund to invest in, with the balanced fund being the default.

The United Methodist Church (2016) has a similar target date arrangement. Workers choose a conservative, moderate, or aggressive investment path. The fund's individualization increases even more because it also considers whether each participant will receive Social Security benefits. Social Security coverage is voluntary for members of the clergy.

In addition, the U.S. mutual fund company, T. Rowe Price (2020), provides two target date funds for each target date. The Retirement fund has 55 percent of its portfolio invested in equities at the retirement date. The Target fund is more conservative, with 42.5 percent invested in equities at the retirement date. However, the largest U.S. mutual funds do not offer multiple target date funds for a single target date. As of 2020, Vanguard and Fidelity, the two largest U.S. providers (Hallez 2020) do not offer target date funds with various risk levels for a single target date. In Denmark, the pension provider Danica (2020) offers a high-risk, medium-risk, and low-risk fund for every target date. The U.S. robo advisor Acorn offers clients a choice of five diversified mutual funds with risk levels running from conservative to aggressive (Haegele 2020).

An advantage of this proposal is that most target date funds are probably riskier than would be preferred by people with a high degree of risk aversion. For example, Shoven and Walton (2020) find that, between 29 February and 23 March 2020, most target date funds for people near retirement lost between 20 and 25 percent. Presumably a feature of target date funds is that they protect participants against large declines near the target date. If participants had a lower risk option available, they would have lost less.

U.S. target date funds generally become more conservative as the participant grows older, starting younger workers in a portfolio that is heavily weighted toward equities. By contrast, the UK's Nest fund, recognizing that people with little stock market experience market may prefer more conservative portfolios, starts young workers out with a relatively conservative portfolio that gradually takes on more risk before later switching to become more conservative as retirement approaches (Nest 2021). Thus, target date fund providers have differing views as to what the glide path of the portfolio should be over the worker's life cycle.

\section{Proposal Two: Offer Access to a Robo Advisor}

Financial advisors can assist with the selection of investments, but they can be expensive and are subject to conflicts of interest (Turner et al. 2016; Turner and Giordano 2020). These conflicts cause some advisors to recommend options that are not in the clients' best interests. An extreme example, studied by Turner et al. (2016), involves a case in which financial advisors recommended that U.S. federal government retirees leave the Thrift Savings Plan, which has extremely low fees of three basis points, and roll over their accounts to investments with substantially higher fees-up to sixty times higher including the advisory fee. In addition, Turner and Giordano (2020) find that some advisors fail to recommend actions that would reduce the advisor's assets under management (AUM), such as failing to recommend purchasing an annuity.

In 2020, the Securities and Exchange Commission (SEC) found that more than half of the advisors it examined were cited for portfolio management violations. These violations included failure to disclose conflicts of interest, such as expense allocations that appeared to benefit proprietary fund clients over non-proprietary fund clients (Knutson 2020). Jacobius (2020) argues that it is increasingly difficult to find financial advisors without conflicts of interest because of industry changes caused by the consolidation of firms. 
While robo advisors are programmed by humans, and thus are potentially subject to the same biases as human advisors, and both robo advisor companies and human advisors have similar financial incentives, robo advisors' business model is to provide advice to many clients at low fees, while human advisors are limited in their number of clients due to the amount of time required per client. Thus, arguably robo advisors may be less susceptible than human advisors to providing bad advice. Robo advisors generally, but not always, do not also provide mutual funds, and thus do not have the incentive to sell their own funds.

While it is not possible to monitor the private conversations that financial advisors have with their clients, it is possible to evaluate the advice provided by computer models (Government Accountability Office (GAO) (2011)). This greater transparency may lead robo advisors to adhere more closely to regulatory requirements than some human advisors.

Robo advisors have emerged in response to investors' needs for financial advice and the high cost of obtaining advice from human advisors (Fisch et al. 2019). Robo advisors are automated on-line services that use computer programs to provide financial advice on investments and manage clients' investment portfolios. Pure robo advisors, with no direct human contact, are generally substantially less expensive than human financial advisors. Some hybrid robo advisors provide access to a human financial advisor for an extra fee. Robo advisors provide financial advice to clients who previously have not received financial advice because they did not have sufficient levels of investible assets, and because they could not afford financial advisors' fees. Thus, robo advisors have the promise of democratizing financial advice by making it available to nearly everyone, not just the wealthy. As with tax preparation software, robo advisors use software to simplify a complex problem-portfolio construction.

Robo advisors have the advantage of economies of scale-one robo advisor (one computer program) can advise many clients. Betterment, for example, has more than 150,000 clients (Egan 2017). As robo advisors acquire more clients and as those clients accumulate more assets, their fees should fall even further. Lower fees may make financial advice accessible to an even larger market of investors who are unwilling to pay for human advisors.

Robo advisors also offer customers convenience. Robo advisors are available at any time and from any location by a client who has access to a computer or smart phone. These features of robo advisors may be particularly appealing to a younger generation, people who are comfortable with technology and who prefer the freedom of flexible times and locations.

The robo advisor, Ellevest, is based on the premise that financial advice should be different for women than men. Ellevest (2020) states that its investment algorithm takes into account that women earn lower pay on average than men, that they will more likely have career breaks, that their earnings tend to peak earlier than men, and that they will on average live longer. A 2020 survey during the 2020 pandemic finds that more than one in four U.S. women workers considered leaving the labor force or reducing their hours because of the extra childcare responsibilities associated with home schooling and remote learning during the pandemic (McKinsey \& Company 2020).

Following Fisch and Turner (2018), we propose that pensions using target date funds offer a robo advisor to help people choose a fund when they enroll. This approach, using a questionnaire to assess the risk tolerance of each person, would help to personalize target date funds in relation to bearing financial market risk. In addition, periodically, perhaps every five years, the participants could use the robo advisor to analyze whether their target date fund continues to be appropriate for their levels of risk aversion. Robo advisors connected with employer-provided individual account pension plans could use data that employers have about their employees, such as age, income, sick leave usage, and family status, to better personalize recommendations, while streamlining the process for participants. 
This approach of investing people with a high degree of risk aversion in more conservative portfolios provides better investment choices in relation to individual levels of risk aversion. The approach can also provide guard rails in that it can moderate against excessive conservatism and excessive risk-taking in portfolios, which could occur when people choose extreme portfolios.

An advantage provided by this approach where a robo advisor helps the participant choose the level of risk is that some target date funds are riskier than others. A person might prefer a higher risk option in some target date funds that are more conservative, but the medium risk option, or an earlier target date, in funds that are more aggressive. For example, in 2020, the T. Rowe Price (2020) fund was 40 percent in fixed income assets, compared to the BlackRock LifePath Index Retirement Fund, which was 60 percent in fixed income assets (Carlson 2021). An unsophisticated pension participant could benefit from the help of a robo adviser in making that distinction. Another issue is that, over time, target date funds, on average, have increased their exposure to equities (Massa et al. 2021).

A trend with robo advisors is efforts to better determine the risk tolerance of clients. The more relevant information robo advisors can gather concerning their clients, the greater the degree of personalization that is possible. A new development may be integrating software that does rebalancing with software that assesses risk tolerance (Kitces 2020).

Shoven and Walton (2020) suggest as an option that defined contribution pension plans offer broadly diversified mutual funds with five different risk levels, with employees choosing two funds so as to more closely approximate their desired risk level. In addition, they suggest that, every five years, employees answer a risk questionnaire to help themselves make sure they have selected the most appropriate two funds, considering their possibly changing level of risk aversion, given their age. Their idea of selecting two funds could be applied to our robo advisor proposal, with the robo advisor choosing for the participant a weighted average of two target date funds to achieve greater personalization of risk.

Usually, neither robo advisors nor target date funds provide financial education, though robo advisors may provide educational materials on their websites. The automated aspect of both approaches to investing relieves individuals from having to make complicated investment decisions. However, both automated approaches have several other possible weaknesses that may need to be addressed.

First, standard questionnaires used by robo advisors to elicit risk preferences may have biases. Kitces (2017) notes that individuals who report being wealthy have a high capacity for bearing risk but may also be highly risk averse. These individuals are often placed in moderately risky portfolios. The clients' unwillingness to bear risk is overlooked because of their ability to bear risk, even though such individuals should be put in low-risk portfolios. Likewise, it can be argued that people with low capacities for bearing risk, but who have a high-risk tolerance, should be in low-risk portfolios.

Second, pension plan sponsors should not necessarily take investor risk preferences as revealed on robo advisor questionnaires as given. Individual risk preferences could change with greater financial knowledge.

Third, existing evaluations of investor risk preferences focus mostly on investor responses to short-term volatility. Retirement assets, however, are invested for the long term, and it is unclear whether many investors comprehend the long-term implications for future account balances and standard of living in retirement of minimizing the shortterm volatility of retirement portfolios. Muller and Turner (2020) find that many people underestimate the effect of fees on future account balances in the long term.

Fourth, robo advisors generally do not help pension participants manage the drawdown phase in retirement. That is an area where further developments are needed. One approach could be for robo advisors to offer tontines, where the payout was not guaranteed as with an annuity but instead varied depending on the investment and mortality experience of the plan (Forman et al. 2021). 


\section{Proposal Three: Informational Interventions}

The first two proposals provide greater personalization to accommodate differences in risk aversion. However, those approaches place the investments of people who report high levels of risk aversion into low-risk portfolios, even if those accentuated levels of risk aversion result from financial illiteracy. That scenario would be costly, leaving many participants with reduced assets in retirement. Robo advisors generally do not correct for that problem.

To avoid this outcome, fund providers could offer an informational intervention to help pension participants make good investment decisions as to the level of risk they bear at the moment they are making those decisions.

We distinguish these informational interventions from formal financial education programs. Informational interventions would involve educating pension participants, but they would differ from traditional financial education methods. Informational interventions would be limited to assisting participants in making specific investment decisions relating to risk, rather than attempting to improve overall financial literacy. Targeted informational interventions have been successfully used in the U.S. to encourage workers to postpone claiming their Social Security benefits (Smith 2020). They have also been used in a survey to change the advice people provide about whether to annuitize (Hurwitz et al. 2020).

Informational interventions can be done different ways, with traditional approaches involving printed material and email. Gamification is a novel approach for helping people understand the role of risk aversion in investment decisions. This innovative method of communicating and educating pension participants could be especially successful among young, technology-adept employees. According to Gordon L. Clark at Oxford University, the electronic games industry "is changing how we design and build" interfaces for defined contribution plans. Gamification transforms engagement from being a chore into a "positive, reinforcing experience ... that encourages learning by doing" (Appell 2020). A computer game format can communicate the effect of various degrees of risk on long-term portfolio outcomes. Gamification is one option for providing an informational intervention, delivered at the moment when people are enrolling in pensions and making investment decisions related to managing risk.

\section{Future Research}

The central issue of this paper is helping unsophisticated pension participants achieve pension portfolios that match their level of risk aversion when there is a large amount of unexplained heterogeneity in risk aversion. This section suggests possible future research to gain a better understanding of this complex issue.

The first point is that further research needs to be done to better understand the determinants of risk aversion. For example, people with low levels of trust in financial markets may be more risk averse. A growing literature addresses the determinants and effects of trust in financial markets and institutions, including pensions (e.g., Bielawska and Turner 2021).

Second, in particular, further research needs to be done on why women tend to be more risk averse than men. For example, research could examine whether women having greater risks to their labor market earnings, in part due to traditionally having greater childcare responsibilities, is a possible factor. During 2020, for U.S. working mothers with children under the age of $18,10 \%$ quit their jobs and 30\% cut their hours because of COVID-19 (Ranji et al. 2021).

Third, while the focus has been on risk aversion as a determinant of portfolio choice, it may be that people's views as to the probability of major financial market risks may vary, which is a topic that could be explored in future research. For example, research has found that people's views vary as to the probability of cuts in U.S. Social Security benefits, with less-educated people tending to view the risks as being greater (Turner et al. 2019).

Fourth, further research could be done on the use of questionnaires to elicit information about people's level of risk aversion. This is the approach used by robo advisors. 
Fifth, further research could be done on how people respond to financial market risks and how to help them to have better responses.

Sixth, research could be done using new data sets. For example, more use could be made of the data that robo advisors have as to how their clients make financial decisions and the reactions of their clients to financial market risks.

Seventh, further research could be done on the use of timely informational interventions to influence people's views as to their own risk aversion and to influence their responses to market risks. For example, information could be done on the effect of informing people of the risk of having low income in retirement when investing overly conservatively.

Eighth, further research could be done on the heterogeneity in the portfolios provided by robo advisors to people in the same age brackets.

Ninth, further research could investigate the issue of the comparison between the biases of human advisors and robo advisors.

\section{Policy Recommendations}

This section considers policy recommendations for countries attempting to expand pension coverage through defined contribution plans and attempting to improve the portfolio outcomes for participants in those types of plans. For example, Spain is working on the development of second-pillar pensions (Dominguez Fabián and Turner 2021).

One of the issues that may discourage some workers from participating in second pillar pensions is knowing how to invest pension accounts. Using target date funds as a default helps deal with this problem. Robo advisors could be used to provide a better match with participants' risk aversion.

The Premium Pension in Sweden is a mandatory, funded and defined contribution plan. Default investment is a target date fund (AP7 2021). It could be further individualized with a robo advisor assisting participants in choosing the appropriate level of risk. The Netherlands is in the process of moving toward greater reliance on defined contribution plans. It also could consider using target date funds as a default.

\section{Conclusions}

The central issue of this paper is analysis and proposals to help unsophisticated pension participants achieve pension portfolios that match their level of risk aversion when there is a large amount of unexplained heterogeneity in risk aversion. Constructing a well-diversified portfolio that reflects a person's level of risk aversion and that involves low fees is an inherently complex task. For many people, this task is made even more difficult, and probably impossible, due to financial illiteracy. Complexity in the portfolio investment decision combined with financial illiteracy could deter some people from participating in individual account pension plans. One solution, in principle, would be a massive effort to provide financial education for millions of pension participants. We argue in this paper for other approaches.

Seeing this problem as a market opportunity, financial services providers have developed products to simplify investment choices. This simplification is seen in the progression from individual stocks to mutual funds to index funds to target date funds. Target date funds are now prevalent among U.S. individual account pension participants.

This paper addresses a problem inherent in target date funds: They do not distinguish differences in risk aversion among people who have the same target date. Empirical studies find high levels of unexplained heterogeneity in risk aversion. That being the case, target date funds cannot solve the problem of heterogeneity in risk aversion by further separating people into demographic groupings other than age that are known to affect risk aversion, such as gender because of the high degree of unexplained heterogeneity in risk aversion. We discuss three approaches for dealing with heterogeneity in risk aversion.

Target date funds could be developed to help pension participants better match their risk preferences by providing them clear risk choices, targeted advice, and timely 
information about the long-term consequences of their choices. The analysis can be applied to other situations not involving target date funds where defaults are used for investing pension participants' portfolios.

Author Contributions: Formal analysis, J.A.T. and B.W.K. All authors have read and agreed to the published version of the manuscript.

Funding: This research received no external funding.

Institutional Review Board Statement: Not applicable.

Informed Consent Statement: Not applicable.

Data Availability Statement: Not applicable.

Conflicts of Interest: The authors declare no conflict of interest.

\section{References}

Almenberg, Johan, and Anna Dreber. 2015. Gender, Stock Market Participation and Financial Literacy. Economics Letters 137: 140-42. [CrossRef]

AP7. 2021. AP7 Såfa. AP7 Såfa lap7.se. Available online: https://www.pensionsmyndigheten.se/ap7-safa (accessed on 10 December 2020).

Appell, Douglas. 2020. Social Media Improves DC Engagement-GPS Speaker. Pensions E Investments, November 9. Available online: https: / /www.pionline.com/retirement-plans/social-media-improves-dc-engagement-gps-speaker?utm_source=p-idefined-contribution\&utm_medium =email\&utm_campaign=20201109\&utm_content=hero-headline\&CSAuthResp=16049367 23084\%3A0\%3A225633\%3A391\%3A24\%3Asuccess\%3A22FC6BCF2B368152788A62FB195AC556\#cci_r=225633 (accessed on 10 December 2020).

Bajtelsmit, Vickie L., and Jack L. VanDerhei. 1997. Risk Aversion and Pension Investment Choices. Positioning Pensions for the Twenty-First Century. Philadelphia: Penn Press.

Bajtelsmit, Vickie L., and Alexandra Bernasek. 1996. Why Do Women Invest Differently Than Men? Financial Counseling and Planning. Available online: https:/ / papers.ssrn.com/sol3/papers.cfm?abstract_id=2238 (accessed on 10 December 2020).

Bielawska, K., and John A. Turner. 2021. Issues of Trust: Pension Plans, Participants and Service Providers. Edited by J. Kolaczkowski, M. Maher, Y. Stevens and J. Werbrouck. London: Edward Elgar.

Borghers, Lex, James J. Heckman, Bart H. H. Golsteyn, and Huub Meijers. 2009. Gender Differences in Risk Aversion and Ambiguity Aversion. Journal of the European Economic Association 7: 549-58. Available online: https://www.nber.org/system/files/working papers/w14713/w14713.pdf (accessed on 10 December 2020).

Brown, David. C., and Shaur W. Davies. 2020. Off Target: On the Underperformance of Target-Date Funds. Available online: https:/ / papers.ssrn.com/sol3/papers.cfm?abstract_id=3707755 (accessed on 10 December 2020).

Campbell, John Y. 2006. Household Finance. Journal of Finance 61: 1553-604. Available online: https:/ / onlinelibrary.wiley.com/doi/ pdf/10.1111/j.1540-6261.2006.00883.x (accessed on 10 December 2020). [CrossRef]

Carlson, Debbie. 2021. Target-Date 2020 Funds Did Well in 2020. Here's Why. Barron's, Jan. 8. Target-Date 2020 Funds Did Well in 2020. Here's Why. Available online: https:/ / webreprints.djreprints.com/57932.html (accessed on 10 December 2020).

Carroll, Gabriel D., James. J. Choi, Dav Laibson, Brigitte C. Madrian, and Andrew Metrick. 2005. Optimal Defaults and Active Decisions. NBER Working Paper 11074. Cambridge: NBER.

Choi, James J., David Laibson, and Brigitte C. Madrian. 2007. 100 Bills on the Sidewalk: Suboptimal Investment in 401(k) Plans. NBER Working Paper 11554. Cambridge: NBER.

Choi, James J., David Laibson, Brigitte C. Madrian, and Andrew Metrick. 2020. Optimal Defaults. AEA Papers and Proceedings 93: 180-85. Available online: https:/ / www.aeaweb.org/articles?id=10.1257/000282803321947010 (accessed on 10 December 2020). [CrossRef]

Cohen, Alma, and Liran Einav. 2007. Estimating Risk Preferences from Deductible Choice. American Economic Review 97: 745-88. Available online: https://www.nber.org/system/files/working_papers/w11461/w11461.pdf (accessed on 10 December 2020). [CrossRef]

Danica. 2020. Danica Pension Balance. Available online: https://danicapension.dk/privat/pension/produkter/risikotal/danicapension-balance (accessed on 10 December 2020).

Dawson, Chris. 2020. Gender Differences in Attitudes towards Risks and Psychological Responses to Loss. Available online: https:/ / privpapers.ssrn.com/sol3/papers.cfm?abstract_id=3697954\&dgcid=ejournal_htmlemail_behavioral:experimental: finance:ejournal_abstractlink (accessed on 10 December 2020).

Dominguez Fabián, Inmaculada, and John A. Turner. 2021. The Evolution of the Spanish Private Pension System: 1994-2019. In The Evolution of Supplementary Pensions: 25 Years of Pension Reform. Edited by J. Kolaczkowski, Y. Stevens and J. Werbrouck. London: Edward Elgar Publishing, Ltd. 
Duarte, Fabian, and Justine Hasting. 2009. Fettered Consumers and Sophisticated Firms: Evidence from Mexico's Privatized Social Security System. Working Paper. New Haven: Department of Economics, Yale University.

Egan, Dan. 2017. Our Evidence-Based Approach to Improving Investor Behavior. Betterment, October 12. Available online: https: //www.betterment.com/resources/investment-strategy/behavioral-finance-investing-strategy/behavioral-testing/ (accessed on 10 December 2020).

Ellevest. 2020. Bring It All Together. Available online: https:/ / www.ellevest.com/ (accessed on 10 December 2020).

Fey, Jan-Christian, Olivia Lerbs, Carolin Schmidt, and Martin Weber. 2020. Risk Attitude and Capital Market Participation: Is There a Gender Investment Gap in Germany? ZEW Discussion Papers 20-080. Mannheim: ZEW-Leibniz Centre for European Economic Research.

Fisch, Jill E., and John A. Turner. 2018. Making a Complex Investment Problem Less Difficult: Robo Target-Date Funds. Journal of Retirement 5: 40-45. Available online: https://www.nber.org/system/files/working_papers/w14713/w14713.pdf (accessed on 10 December 2020). [CrossRef]

Fisch, Jill E., Marion Labouré, and John A. Turner. 2019. The Emergence of the Robo-advisor. In The Disruptive Impact of FinTech on Retirement Systems. Edited by Julie Agnew and Olivia S. Mitchell. Oxford: Oxford University Press, pp. 13-37.

Forman, Jonathan B., Richard Fullmer, and John A. Turner. 2021. Tontines and Collective Annuities: Risk-Sharing Lessons from an International Survey. Pension Policy Center Working Paper 21-02. Washington: Pension Policy Center.

Government Accountability Office (GAO). 2011. Improved Regulation Could Better Protect Participants from Conflicts of Interest. Available online: http:/ / www.gao.gov/products/GAO-11-119 (accessed on 10 December 2020).

Guiso, Luigi, and Monica Paiella. 2007. Risk Aversion, Wealth, and Background Risk. European University Institute Working Paper ECO 2007/47. Available online: https: / cadmus.eui.eu/bitstream/handle/1814/7501/ECO-2007-47.pdf? sequence=1 (accessed on 10 December 2020).

Guiso, Luigi, Paola Sapienza, and Luigi Zingales. 2004. The Role of Social Capital in Financial Development. American Economic Review 94: 526-56. [CrossRef]

Haegele, Bob. 2020. Acorns Review 2021: Invest Your Spare Change. Modest Money, Dec. 26. Acorns Review 2021: Invest Your Spare Change-Modest Money. Available online: https:/ / www.doughroller.net/investing/acorns-review-how-to-nickel-and-dimeyour-way-to-wealth/ (accessed on 10 December 2020).

Hallez, Emile. 2020. Sales, Returns Push TDF Assets Up by $\$ 290$ Billion in 2019. Investment News, February 5. Available online: https:/ / www.investmentnews.com/target-date-sales-returns-up-2019-187835\#: \{\}:text=After\%20Vanguard\%2C \%20the \% 20three\%20largest,American\%20Funds\%20(\%24152.2\%20billion) (accessed on 10 December 2020).

Harrison, Glenn W., Morten I. Lau, and E. Elisabet Rutstrőm. 2007. Estimating Risk Attitudes in Denmark: A Field Experiment. Scandinavian Journal of Economics 109: 341-68. [CrossRef]

Hinz, Richard P., David D. McCarthy, and John A. Turner. 1996. Are Women Conservative Investors? Gender Differences in ParticipantDirected Pension Investments. In Positioning Pensions for the 21st Century. Philadelphia: University of Pennsylvania Press, pp. 91-103. Available online: https:// repository.upenn.edu/cgi/viewcontent.cgi?article=1593\&context=prc_papers (accessed on 10 December 2020).

Hurwitz, Abigail, Olivia S. Mitchell, and Orly Sade. 2020. Testing Methods to Enhance Longevity Awareness. Working Paper 2021-07. Philadelphia: Pension Research Council.

Jacobius, Arleen. 2020. Consultants Free of Conflicts Becoming a Bit Harder to Find. Pensions \& Investments, November 30.

Jacobs, Deborah L. 2013. The Trouble with Target Date Mutual Funds. Forbes, November 11. Available online: https:/ / www.forbes.com/ sites/deborahljacobs/2013/11/11/the-trouble-with-target-date-mutual-funds/\#45a8064a4dcb (accessed on 10 December 2020).

Katzeff, Paul. 2016. 401(k) Experts Warn When NOT to Use a Target Date Fund. Investor's Business Daily, November 25. Available online: http:/ / www.investors.com/etfs-and-funds/retirement/401k-experts-warn-when-not-to-use-a-target-date-fund/ (accessed on 10 December 2020).

Khemka, Gaurav, Mogens Stephensen, and Geoffrey J. Warren. 2020. How Suboptimal Are Age-Based Life-Cycle Investment Products? International Review of Financial Analysis 73: 101619. [CrossRef]

Kitces, Michael. 2017. Adopting a Two-Dimensional Risk-Tolerance Assessment Process. The Nerd's Eye View, January 25. Available online: https: / / bit.ly /2zAKB46 (accessed on 10 December 2020).

Kitces, Michael. 2020. The Latest in Financial Adviser \#FinTech. February 3. Available online: https://www.kitces.com/ blog/the-latest-in-financial-advisor-fintech-february-2020/?utm_source=Nerd\%E2\%80\%99s+Eye+View+\%7C+Kitces.com\& utm_campaign=95221fa9db-NEV_MAILCHIMP_LIST\&utm_medium=email\&utm_term=0_4c81298299-95221fa9db-57149837 (accessed on 10 December 2020).

Knutson, Ted. 2020. Financial Advisers Faulted for Deficiencies in Vast Majority of SEC Exams. Forbes, November 9. Available online: https:/ / www.forbes.com/sites/tedknutson/2020/11/09/financial-advisers-faulted-for-deficiencies-in-vast-majorityof-sec-exams/?sh=2cefc4906618 (accessed on 10 December 2020).

Li, Ling, Shuyi Lee, and Deming Luo. 2021. Gender Differences in Stock Market Participation: Evidence from Chinese Households. Available online: https:/ / papers.ssrn.com/sol3/papers.cfm?abstract_id=3775478\&dgcid=ejournal_htmlemail_behavioral: experimental:finance:ejournal_abstractlink (accessed on 10 December 2020).

Lloyd, Neil. 2018. Default Investment Strategies: Will Improved Managed Account Solutions Challenge Target-Date Fund Dominance? Benefits Quarterly, First Quarter. Toronto: Brookfield, pp. 21-25. Available online: https://search.proquest.com/openview/6c98ba75b170 920c69fa347bf9b45943/1?pq-origsite=gscholar\&cbl=4616 (accessed on 10 December 2020). 
Lusardi, Annamaria, and Olivia S. Mitchell. 2008. Planning and Financial Literacy: How Do Women Fare? American Economic Review 98: 413-17. [CrossRef]

Lusardi, Annamaria, and Olivia S. Mitchell. 2014. The Economic Importance of Financial Literacy: Theory and Evidence. Journal of Economic Literature 52: 5-44. [CrossRef] [PubMed]

Lusardi, Annamaria, Pierre-Carlic Michaud, and Olivia S. Mitchell. 2017. Assessing the Impact of Financial Education Programs: A Quantitative Model. Working Paper PRC WP2018-4. Philadelphia: Pension Research Council. Available online: https: / / repository.upenn.edu/cgi/viewcontent.cgi?article=1020\&context=prc_papers (accessed on 10 December 2020).

Luxenberg, Stan. 2013. Bogle: The Problem with Target-Date Funds. Wealth Management, June 25. Available online: http://www. wealthmanagement.com/mutual-funds/bogle-problem-target-date-funds (accessed on 10 December 2020).

Martensen, Rita. 2008. Are Men Better Investors than Women? Gender Differences in Mutual Fund and Pension Investments. Journal of Financial Services Marketing 13: 72-81. [CrossRef]

Massa, Massimo, Rabih Moussawi, and Andrei Simonov. 2021. Target-Date Funds Exploit Their Investors' Long Time Horizons. Here's How. Institutional Investor, March 23. Available online: https://www.institutionalinvestor.com/article/b1r2xbpcxtv2r2 /Target-Date-Funds-Exploit-Their-Investors-Long-Time-Horizons-Here-s-How?utm_medium=email\&utm_campaign=The\% 20Essential\%20II\%2003242021\&utm_content=The\%20Essential\%20II\%2003242021\%20CID_5f187e834e5a37458509fdfe92fe07f7 \&utm_source=CampaignMonitorEmail\&utm_term=TaregetcDate\%20Funds\%20Exploit\%20Their\%20Investors \%20Long\%20 Time\%20Horizons\%20Heres\%20How (accessed on 10 December 2020).

McGrath, Maggie. 2021. Sallie Krawcheck Leads Ellevest to a Landmark \$1 Billion in Assets under Management. Forbes. March 23. Available online: https:/ / www.forbes.com/sites/maggiemcgrath/2021/03/23/sallie-krawcheck-grows-ellevest-to-1-billionin-assets-under-management/?cdlcid=5d0105751802c8c524b9f00c\&utm_campaign=dailydozen\&utm_medium=email\&utm_ source $=$ newsletter\&sh $=4 \mathrm{c} 1507 \mathrm{df} 2395$ (accessed on 10 December 2020).

McKinsey \& Company. 2020. Women in the Workplace 2020. Available online: https://www.mckinsey.com/featured-insights/ diversity-and-inclusion/women-in-the-workplace\# (accessed on 10 December 2020).

Mitchell, Olivia S., and John A. Turner. 2010. Labor Market Uncertainty and Pension System Performance. In Performance of Privately Managed Pension Funds. Edited by Richard P. Hinz, Heinz P. Rudolf, Pablo Antolin and Juan Yermo. Washington: World Bank, pp. 119-58. Available online: https:/ / openknowledge.worldbank.org/bitstream/handle/10986/2405/527090PUB0pens101Official0 Use0only1.txt?sequence=2 (accessed on 10 December 2020).

Mitchell, Olivia S., and Stephen P. Utkus. 2020. Target Date Plans and Portfolio Choice in 401(k) Plans. Working Paper PRC WP2020-03. Philadelphia: Pension Research Council.

Muller, Leslie A., and John A. Turner. 2016. Strategic Complexity in Investment Management Fee Disclosures. Financial Services Review 25: 215-34.

Muller, Leslie A., and John A. Turner. 2020. Financial Literacy, the "High Fee Puzzle", and Knowledge about the Importance of Fees. Journal of Retirement 8: 84-91.

Nest. 2021. Nest Retirement Date Funds. London: Nest Pensions Retirement Date Funds I Nest Pensions.

Ranji, Usha, Brittni Frederiksen, Alina Salganicoff, and Michelle Long. 2021. Women, Work, and Family during COVID-19: Findings from the KFF Women's Health Survey. KFF, March 22. Available online: https:/ / www.kff.org/womens-health-policy/issue-brief/ women-work-and-family-during-covid-19-findings-from-the-kff-womens-health-survey/ (accessed on 10 December 2020).

Shen, Sally, and John A. Turner. 2018. Conflicted Advice about Portfolio Diversification. Financial Services Review 27: 47-82. Available online: https://globalriskinstitute.org/publications/conflicted-advice-about-portfolio-diversification/ (accessed on 10 December 2020). [CrossRef]

Shoven, John B., and Daniel B. Walton. 2020. An Analysis of the Performance of Target Date Funds. NBER Working Paper 27971. Cambridge: NBER.

Smith, Barbara A. 2020. Can Informational Interventions Be Effectice Policy Tools? An Initial Assessment of the Social Security Statement. Social Security Bulletin 80: 1.

T. Rowe Price. 2020. Target Date Glide Path Design. Available online: https://www.troweprice.com/financiahttps://www. troweprice.com/financial-intermediary/us/en/insights/articles/2015/q4/glide-path-design.htmlintermediary/us / en/ insights/articles/2015/q4/glide-path-design.html (accessed on 10 December 2020).

Tepper, T. 2020. Ellevest Review 2020: A Woman-Centric Robo-Advisor. Forbes. September 30. Available online: https://www.forbes. com/advisor/investing/ellevest-robo-advisor-review/ (accessed on 10 December 2020).

The People's Pension. 2016. Home. Available online: https://thepeoplespension.co.uk/ (accessed on 10 December 2020).

Thrift Savings Plan. 2021. Lifecycle (L) Funds. Available online: https:/ /www.tsp.gov/ (accessed on 10 December 2020).

Turner, John A. 2003. Errors Workers Make in Managing 401(k) Investments. Benefits Quarterly 19: 75-82.

Turner, John A., and David D. McCarthy. 2000. Pension Education: Does It Help? Does It Matter? Benefits Quarterly 16: 64-72.

Turner, John A., and Shelley Giordano. 2020. AUM-Based Compensation and Financial Advice. Journal of Retirement 8: 84-99. [CrossRef]

Turner, John A., and Sophie M. Korczyk. 2004. Pension Participant Knowledge about Plan Fees. AARP Data Digest 105, November. Available online: http:/ / assets.aarp.org/rgcenter/post-import/dd105_fees.pdf (accessed on 10 December 2020).

Turner, John A., Bruce W. Klein, and Norman P. Stein. 2016. Financial Illiteracy Meets Conflicted Advice: The Case of Thrift Savings Plan Rollovers. Journal of Retirement Spring 3: 47-66. [CrossRef] 
Turner, John A., Jules Lichtenstein, and Jennifer E. Brown. 2018. Mandating Pension Auto Enrollment in the United Kingdom: Implications for the United States. Journal of Retirement 6: 82-92. [CrossRef]

Turner, John A., Saisai Zhang, Gerard Hughes, and David M. Rajnes. 2019. Irrational Expectations, Future Social Security Benefits, and Life Cycle Planning. Journal of Retirement 6: 60-68.

United Methodist Church. 2016. Wespath Benefits and Investments. Available online: http://www.wespath.org/retirement/services/ lifestage-investment-management-service/\#3 (accessed on 10 December 2020).

Watson, John, and Mark McNaughton. 2007. Gender Differences in Risk Aversion and Expected Retirement Benefits. Financial Analysts Journal 63: 52-62. Available online: https://www.researchgate.net/profile/John_Watson20/publication/228279490_ Gender_Differences_in_Risk_Aversion_and_Expected_Retirement_Benefits/links/53cf4e410cf25dc05cfae0cc.pdf (accessed on 10 December 2020). [CrossRef] 